\title{
LITERATURE REVIEW PROSES PENYUSUTAN DOKUMEN REKAM MEDIS DI RUMAH SAKIT
}

\author{
Hanifah Apriliandawati ${ }^{1}$, Antik Pujihastuti ${ }^{2}$ \\ hanifahaprliandaw@gmail.com,att2a2000@yahoo.com
}

\begin{abstract}
Medical record shrinkage carried out gradually starting from sorting, moving, assessing and destroying. Obstacles in the implementation of shrinkage medical record are the limited human resources in the filing section and the infrastructure to support the shrinkage of medical record is inadequate. The purpose of this research was to determine the implementation of depreciation of medical record. This research method used a literature review design. The results showed that the sorting of medical record documents was carried out based on a 5-year period by looking at the year the patient's last visit was treated. Transfer of medical record documents is done by moving medical record documents from the active room to the inactive room. Assessment of medical record documents is in accordance with the use and importance of medical record documents. Obstacles that hinder the implementation of shrinkage of medical record documents are human resources and infrastructure. Conclusion from the results of this study, depreciation was carried out by sorting out the medical record documents then moving the medical record documents that were inactive, after which an assessment of the medical record documents was carried out according to the usefulness and importance of the medical record documents so that they could identify obstacles in the implementation of shrinkage of medical record documents.
\end{abstract}

Keyword : Depreciation, Retention, Medical Record

\begin{abstract}
Abstrak
Penyusutan berkas rekam medis dilakukan secara bertahap yaitu dimulai dari pemilahan, pemindahan, penilaian dan pemusnahan. Kendala dalam pelaksanaan penyusutan yaitu terbatasnya sumber daya manusia di bagian filing dan sarana prasarana untuk menunjang pelaksanaan penyusutan dokumen rekam medis belum memadai. Tujuan penelitian ini untuk mengetahui pelaksanaan penyusutan dokumen rekam medis. Metode penelitian ini menggunakan desain literature review. Hasil penelitian menunjukkan bahwa pemilahan dokumen rekam medis dilakukan berdasarkan periode 5 tahun dengan cara melihat tahun kunjungan terakhir pasien tersebut berobat. Pemindahan dokumen rekam medis dilakukan dengan cara memindahkan dokumen rekam medis dari ruangan aktif ke ruangan inaktif. Penilaian dokumen rekam medis sesuai dengan kegunaan dan kepentingan dokumen rekam medis. Kendala yang menghambat pelaksanaan penyusutan dokumen rekam medis yaitu sumber daya manusia dan sarana prasarana. Simpulan dari hasil penelitian ini penyusutan dilakukan dengan memilah dokumen rekam medis kemudian memindahkan dokumen rekam medis yang sudah inaktif setelah itu dilakukan penilaian dokumen rekam medis sesuai dengan kegunaan dan kepentingan dokumen rekam medis sehingga dapat mengetahui penghambat dalam pelaksanaan penyusutan dokumen rekam medis.
\end{abstract}

Kata Kunci : Penyusutan, Retensi, Rekam Medis 


\section{PENDAHULUAN}

Rekam medis menurut PerMenKes RI No 269/MENKES/PER/III/2008 Bab I Pasal 1 adalah berkas yang berisikan catatan dan dokumen tentang identitas pasien, pemeriksaan, pengobatan, tindakan dan pelayanan lain yang telah diberikan kepada pasien. Rekam medis pasien rawat inap di rumah sakit wajib disimpan sekurang-kurangnya untuk jangka waktu lima tahun terhitung dari tanggal terakhir pasien berobat atau dipulangkan. Setelah batas waktu lima tahun dilampaui rekam medis dapat dimusnahkan kecuali ringkasan pulang dan persetujuan tindakan medik.

Penyusutan adalah suatu kegiatan pengurangan berkas rekam medis dari rak penyimpanan dengan penentuan jangka waktu penyimpanan berkas rekam medis ditentukan atas dasar nilai kegunaan tiap-tiap berkas rekam medis. Penyusutan berkas rekam medis dilakukan secara bertahap yaitu dimulai dari pemilahan, pemindahan, penilaian dan pemusnahan (Depkes RI, 2006).

Menurut penelitian Rahayu (2012) permasalahan dalam pelaksanaan penyusutan dokumen rekam medis di RS Siloam Kebon Jeruk yaitu pemindahan dokumen rekam medis inaktif belum dilakukan. Dalam penelitian Ariyani (2017) proses dalam pelaksanaan penyusutan dokumen rekam medis belum sesuai karena dokumen rekam medis yang belum berusia 5 tahun sudah dilakukan pemilahan. Selain itu kendala yang ditemukan yaitu kurangnya sumber daya manusia sehingga menghambat petugas untuk melaksanakan penyusutan sedangkan jumlah dokumen rekam medis selalu meningkat hal ini dapat mengakibatkan penumpukan dokumen rekam medis.

Berdasarkan hasil penelitian tersebut dapat disimpulkan bahwa pelaksanaan penyusutan dokumen rekam medis masih terdapat beberapa kendala yang menghambat proses pelaksanaan penyusutan dokumen rekam medis dan belum sesuai dengan kebijakan yang ada. Berdasarkan uraian diatas, penulis tertarik untuk melakukan studi literature review mengenai "Proses Penyusutan Dokumen Rekam Medis di Rumah Sakit".

\section{METODE}

Rancangan penelitian menggunakan desain literature review yaitu review yaitu penelitian yang mengkaji, menelaah artikel-artikel penelitian dengan mengintegrasikan dan menarik kesimpulan tentang proses pelaksanaan penyusutan dokumen rekam medis. Subjek dalam penelitian ini adalah 5 jurnal dengan populasi petugas rekam medis.
HASIL DAN PEMBAHASAN

\section{A. Hasil Penelitian}

Tabel 1. Hasil Ekstraksi Data

\begin{tabular}{|c|c|c|}
\hline $\begin{array}{l}\text { Author } \\
\text { (Tahun) }\end{array}$ & Judul & Outcome \\
\hline Betri, 2020 & $\begin{array}{l}\text { Analisa } \\
\text { Pelaksanaan } \\
\text { Retensi } \\
\text { Dokumen } \\
\text { Rekam Medis }\end{array}$ & 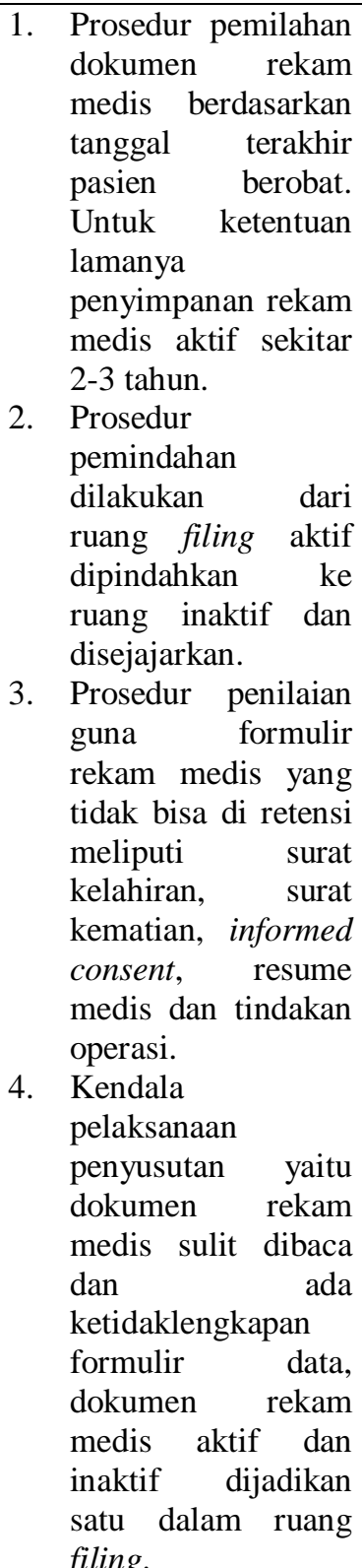 \\
\hline $\begin{array}{l}\text { Nuraini \& } \\
\text { Rohmiyati, } \\
2017\end{array}$ & $\begin{array}{l}\text { Analisis } \\
\text { Penyusutan } \\
\text { Arsip Rekam } \\
\text { Medis Dalam } \\
\text { Rangka } \\
\text { Penyelamatan } \\
\text { Arsip }\end{array}$ & $\begin{array}{l}\text { 1. Prosedur pemilahan } \\
\text { arsip rekam medis } \\
\text { dilakukan setelah } \\
\text { jangka waktu 5 } \\
\text { tahun terakhir } \\
\text { kunjungan pasien } \\
\text { berobat. } \\
\text { 2. } \\
\begin{array}{l}\text { Prosedur } \\
\text { pemindahan arsip }\end{array}\end{array}$ \\
\hline
\end{tabular}




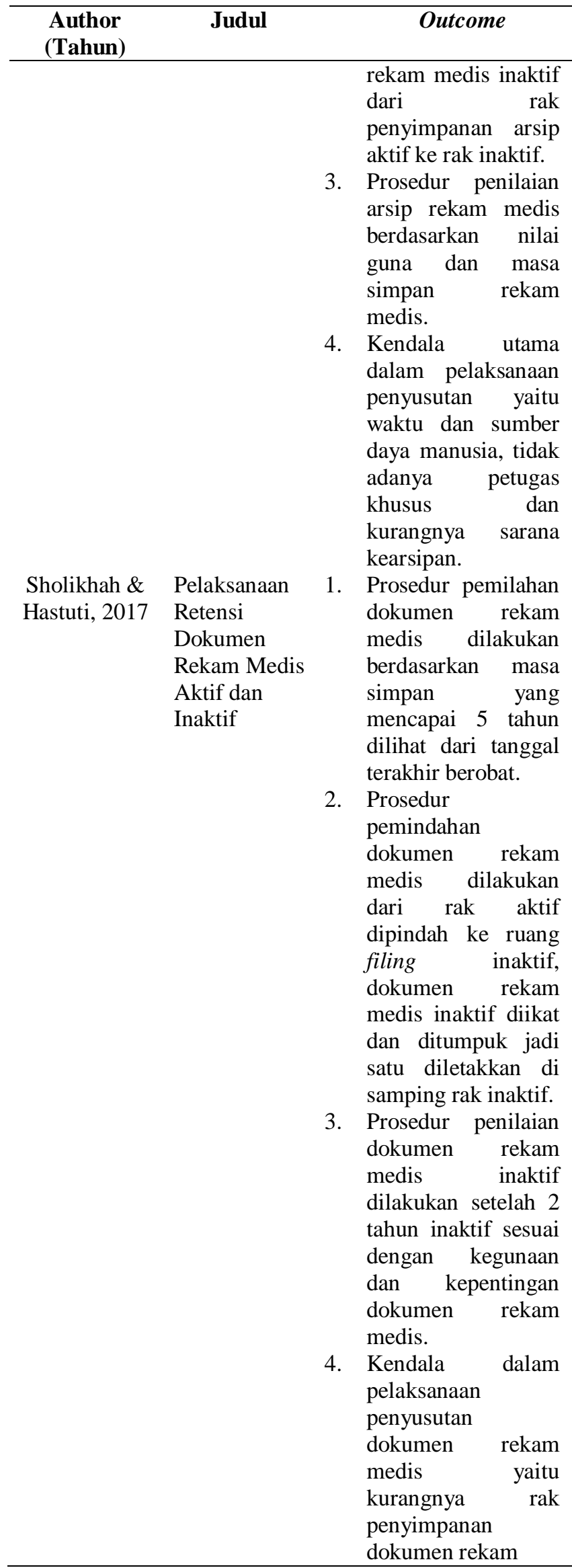

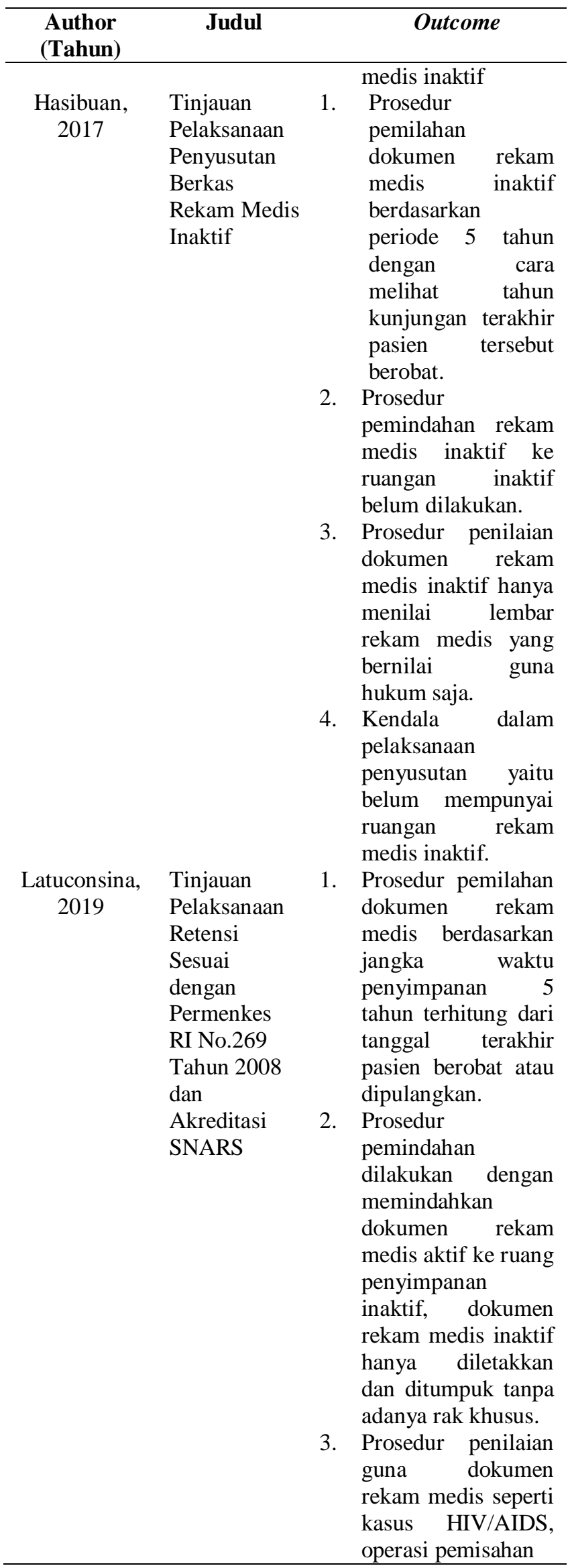




\begin{tabular}{clr}
\hline $\begin{array}{c}\text { Author } \\
\text { (Tahun) }\end{array}$ & Judul & \multicolumn{2}{c}{ Outcome } \\
\hline & kembar siam, \\
& operasi \\
& penyesuaian organ \\
& kelamin, SARS, flu \\
& burung tidak \\
& disimpan \\
& selamanya. \\
& Kendala dalam \\
& pelaksanaan \\
& penyusutan \\
& dokumen rekam \\
& medis yaitu tidak \\
& ada petugas khusus \\
& dan tidak adanya \\
& rak \\
& dokumen khusus \\
& medis inaktif. \\
\hline
\end{tabular}

Prosedur pemilahan dokumen rekam medis berdasarkan jangka waktu penyimpanan 5 tahun dilihat dari tanggal terakhir pasien berobat atau dipulangkan terdapat pada penelitian Sholikhah \& Hastuti (2017) ; Hasibuan (2017) ; Latuconsina (2019) ; Nuraini \& Rohmiyati (2017). Sedangkan pemilahan dokumen rekam medis dengan ketentuan lama penyimpanan dokumen rekam medis aktif sekitar 2-3 tahun terdapat pada penelitian Betri (2020).

Prosedur pemindahan dokumen rekam medis dari ruang filing aktif ke ruang filing inaktif terdapat pada penelitian Betri (2020) ; Sholikhah \& Hastuti (2017) ; Latuconsina (2019) ; Nuraini \& Rohmiyati (2017). Sedangkan pada penelitian Hasibuan (2017) pemindahan dokumen rekam medis inaktif belum dilakukan karena belum tersedianya ruangan rekam medis inaktif.

Prosedur penilaian guna dokumen rekam medis dilakukan setelah 2 tahun inaktif sesuai dengan kegunaan dan kepentingan dokumen rekam medis terdapat pada penelitian Sholikhah \& Hastuti (2017) ; Nuraini \& Rohmiyati (2017). Sedangkan pada penelitian Betri (2020) Formulir rekam medis yang tidak bisa di retensi meliputi surat kelahiran, surat kematian, informed consent, resume medis dan tindakan operasi. Pada penelitian Hasibuan (2017) penilaian dokumen rekam medis hanya menilai lembar rekam medis yang bernilai guna hukum saja. Pada penelitian Latuconsina (2019) penilaian dokumen rekam medis yang dianggap sangat bernilai hanya disimpan dalam jangka waktu penyimpanan selama 5 tahun untuk dokumen rekam medis aktif dan 5 tahun untuk dokumen rekam medis inaktif.

Kendala dalam pelaksanaan penyusutan dokumen rekam medis tidak adanya petugas khusus yang menangani kegiatan penyusutan dokumen rekam medis terdapat pada penelitian Latuconsina (2019) ; Nuraini \& Rohmiyati (2017). Sedangkan pada penelitian Betri (2020) ; Sholikhah \& Hastuti (2017) ; Hasibuan (2017) kendala dalam pelaksanaan penyusutan dokumen rekam medis yaitu dokumen rekam medis sulit dibaca, ada ketidaklengkapan formulir data dan sarana prasarana yang menunjang kegiatan penyusutan dokumen rekam medis belum memadai.

\section{B. Pembahasan}

1. Prosedur Pemilahan Dokumen Rekam Medis Berdasarkan penelitian Nuraini \& Rohmiyati (2017) ; Sholikhah \& Hastuti (2017) ; Hasibuan (2017) ; Latuconsina (2019) menyebutkan bahwa pemilahan dokumen rekam medis dilakukan berdasarkan jangka waktu penyimpanan 5 tahun terhitung dari tanggal terakhir pasien berobat atau berkunjung ke rumah sakit. Hal ini didukung oleh penelitian Susilo (2019) bahwa pemilahan dokumen rekam medis inaktif berpedoman pada jangka waktu 5 tahun terakhir pasien berobat. Hal tersebut sudah sesuai dengan PerMenKes RI No 269/MENKES/PER/III/2008 Bab IV Pasal 8 Ayat 1 yang menyebutkan bahwa rekam medis pasien rawat inap di rumah sakit wajib disimpan sekurang-kurangnya untuk jangka waktu 5 tahun terhitung dari tanggal terakhir pasien berobat atau dipulangkan.

Berdasarkan penelitian Betri (2020) menyebutkan bahwa pemilahan dokumen rekam medis dilakukan berdasarkan tanggal terakhir pasien berobat tetapi untuk ketentuan lamanya penyimpanan rekam medis aktif sekitar 2-3 tahun karena kapasitas penyimpanan dokumen rekam medis yang sudah terlalu penuh. Hal tersebut belum sesuai dengan PerMenKes RI No 269/MENKES/PER/III/2008 Bab IV Pasal 8 Ayat 1.

2. Prosedur Pemindahan Dokumen Rekam Medis Berdasarkan penelitian Betri (2020); Sholikhah \& Hastuti (2017) ; Latuconsina (2019) ; Nuraini \& Rohmiyati (2017) menjelaskan bahwa pemindahan dokumen rekam medis aktif dipindahkan ke ruang filing inaktif. hal ini sudah sesuai dengan Depkes RI (2006) yang menjelaskan bahwa rak penyimpanan dokumen rekam medis tidak aktif dapat diletakkan diruang tersendiri terpisah dari rak penyimpanan dokumen rekam medis aktif.

Berdasarkan penelitian Hasibuan (2017) menyebutkan bahwa pemindahan dokumen rekam medis masih belum dilakukan dikarenakan belum adanya ruangan rekam medis inaktif. Hal ini selaras dengan 
penelitian Abidin \& Halid (2018) yang menjelaskan belum melakukan pemindahan rekam medis in aktif ke ruangan inaktif. karena belum mempunyai ruangan rekam medis inaktif. Hal tersebut belum sesuai dengan Depkes RI (2006) yang menjelaskan penyimpanan dokumen rekam medis inaktif diletakkan terpisah dengan penyimpanan dokumen rekam medis aktif.

3. Prosedur Penilaian Dokumen Rekam Medis

Berdasarkan penelitian Betri (2020); Sholikhah \& Hastuti (2017) ; Nuraini \& Rohmiyati (2017) menjelaskan bahwa penilaian dokumen rekam medis dilakukan setelah 2 tahun inaktif sesuai dengan kegunaan dan kepentingan dokumen rekam medis. Dokumen rekam medis yang disimpan yaitu meliputi ringkasan masuk dan keluar, resume medis, surat kelahiran, surat kematian, informed consent, laporan operasi, identifikasi bayi baru lahir, laporan persalinan dan dokumen yang dianggap penting. Penelitian yang mendukung yaitu Lestari et al. (2019) yang menjelaskan penilaian berkas rekam medis dilakukan ke berkas rekam medis yang sudah habis masa simpannya dalam jangka 5 tahun aktif dan 2 tahun inaktif, untuk berkas rekam medis yang dinilai yaitu lembar data identitas pasien, surat persetujuan tindakan (informed consent), laporan operasi dan anastesi, resume medis, identifikasi bayi baru lahir dan lembar kematian. Hal tersebut sudah sesuai dengan PerMenKes RI No 269/MENKES/PER/III/2008 Bab IV Pasal 8 ayat 2 .

Berdasarkan penelitian Hasibuan (2017) ; Latuconsina (2019) menyebutkan bahwa penilaian dokumen rekam medis hanya menilai lembar rekam medis yang bernilai guna hukum saja dan kasus HIV/AIDS, operasi pemisahan kembar siam, operasi penyesuaian organ kelamin, SARS, flu burung tidak disimpan selamanya. Hal tersebut belum sesuai dengan Sudra (2013) yang menjelaskan bahwa dokumen rekam medis yang dianggap sangat bernilai umumnya akan disimpan selamanya.

4. Kendala Dalam Pelaksanaan Penyusutan Dokumen Rekam Medis

Berdasarkan penelitian Betri (2020); Sholikhah \& Hastuti (2017) ; Hasibuan (2017) menjelaskan bahwa kendala pelaksanaan penyusutan dokumen rekam medis yaitu kurangnya sarana prasarana untuk menunjang pelaksanaan penyusutan dokumen rekam medis, seperti rak penyimpanan dokumen inaktif dan ruang filing dokumen rekam medis inaktif. Hal ini belum sesuai dengan
PerMenKes RI No 269 tahun 2008 Bab III Pasal 7 yang menjelaskan bahwa sarana pelayanan kesehatan wajib menyediakan fasilitas yang diperlukan dalam rangka penyelenggaraan rekam medis dan belum sesuai dengan teori SNARS MIRM 10 poin 2, rumah sakit belum menjamin keamanan dan kerahasiaan rekam medis karena dokumen rekam medis hanya ditumpuk disamping rak.

Berdasarkan penelitian Latuconsina (2019) ; Nuraini \& Rohmiyati (2017) menyebutkan kendala yang dialami dalam pelaksanaan penyusutan dokumen rekam medis yaitu tidak adanya petugas khusus dalam pelaksanaan penyusutan dokumen rekam medis. Hasil penelitian yang mendukung yaitu Susilo (2019) yang menjelaskan belum adanya petugas khusus untuk pelaksanaan penyusutan sehingga dapat menyebabkan penumpukan dan kerusakan di rak filing. Hal tersebut belum sesuai dengan PerMenKes RI No 269 tahun 2008 Bab IV pasal 8 ayat 4 yang menjelaskan bahwa penyimpanan rekam medis dilaksanakan oleh petugas yang ditunjuk oleh pimpinan sarana pelayanan kesehatan.

\section{SIMPULAN}

1. Prosedur pemilahan dokumen rekam medis dilakukan dengan cara melihat jangka waktu penyimpanan yaitu 5 tahun terhitung dari tanggal terakhir pasien berobat atau dipulangkan. Tetapi pada proses penyimpanan dokumen rekam medis terdapat ketentuan penyimpanan rekam medis aktif yaitu sekitar 2-3 tahun.

2. Prosedur pemindahan dokumen rekam medis dilakukan dengan cara memindahkan dokumen rekam medis aktif ke ruang filing inaktif. Tetapi ada juga yang belum memindahkan dokumen rekam medis dari ruang aktif ke ruangan inaktif, hal tersebut dikarenakan belum adanya ruangan khusus untuk dokumen rekam medis inaktif.

3. Prosedur penilaian dokumen rekam medis dilakukan setelah 2 tahun inaktif sesuai dengan kegunaan dan kepentingan dokumen rekam medis. Dokumen rekam medis yang disimpan yaitu meliputi ringkasan masuk dan keluar, resume medis, surat kelahiran, surat kematian, informed consent, laporan operasi, identifikasi bayi baru lahir, laporan persalinan dan dokumen yang dianggap penting. Tetapi dalam pelaksanaannya masih ada penilaian dokumen rekam medis inaktif yang hanya menilai lembar rekam medis bernilai guna hukum saja dan kasus-kasus tertentu yang 
dianggap sangat bernilai tidak disimpan selamanya.

4. Kendala dalam proses penyusutan dokumen rekam medis yaitu dokumen rekam medis sulit dibaca, ketidaklengkapan formulir data, tidak adanya petugas khusus dan kurangnya sarana prasarana untuk menunjang pelaksanaan penyusutan dokumen rekam medis, seperti rak penyimpanan dokumen inaktif dan belum adanya ruang filing dokumen rekam medis inaktif.

\section{SARAN}

1. Apabila rumah sakit akan melakukan penyusutan dokumen rekam medis sebaiknya perlu diperhatikan ketersediaan sarana dan prasarana penunjang penyusutan dokumen rekam medis seperti rak penyimpanan dokumen rekam medis inaktif dan ruang khusus untuk menyimpan dokumen rekam medis inaktif agar dokumen rekam medis aktif dan inaktif disimpan secara terpisah sehingga memudahkan petugas untuk melakukan pencarian ulang.

2. Apabila melaksanakan penilaian dokumen rekam medis sebaiknya petugas melakukan penilaian secara menyeluruh sesuai dengan nilai primer (ALFRED). Untuk kasus-kasus yang memiliki nilai guna primer dan sekunder disimpan untuk selamanya dan memperhatikan PerMenKes RI No 269/MENKES/PER/III/2008 Bab IV Pasal 8 Ayat 2 yang menyebutkan bahwa rekam medis setelah batas waktu penyimpanan 5 tahun dilampaui dapat dimusnahkan kecuali ringkasan pulang dan persetujuan tindakan medis.

3. Apabila rumah sakit akan melakukan penyusutan dokumen rekam medis sebaiknya dilakukan pelatihan kepada petugas tentang prosedur penyusutan dokumen rekam medis dan penunjukan petugas khusus untuk melaksanakan penyusutan agar petugas tidak memiliki tugas pokok ganda sehingga pelaksanaannya bisa lebih efisien. Serta petugas perlu berkoordinasi dengan tenaga kesehatan lain terkait kelengkapan dalam pengisian dokumen rekam medis sesuai ketentuan yang berlaku di rumah sakit tersebut agar tidak menghambat pelaksanaan retensi dokumen rekam medis.

\section{DAFTAR PUSTAKA}

Ariyani, R. (2017). Pelaksanaan Penyusutan Berkas Rekam Medis di RST Dr. Soedjono
Magelang Tahun 2017 [KTI].Yogyakarta : STIKes Jenderal Achmad Yani Yogyakarta.

Betri, E. (2020). Analisa Pelaksanaan Retensi Dokumen Rekam Medis Di Rsu Muhammadiyah Ponorogo. Jurnal Delima Harapan 7(2), 69-81.

Depkes. (2006). Pedoman Penyelenggaraan dan Prosedur Rekam Medis Rumah Sakit di Indonesia. Jakarta: Direktorat Jenderal Bina Pelayanan Medik.

Hasibuan, A. S. (2017). Tinjauan Pelaksanaan Penyusutan Berkas Rekam Medis Inaktif di Rumah Sakit Umum Imelda Pekerja Indonesia (IPI) Medan Tahun 2016. Jurnal Ilmiah Perekam dan Informasi Kesehatan Imelda 2(1), 192-199.

Komisi Akreditasi Rumah Sakit. (2017). Standar Nasional Akreditasi Rumah Sakit Edisi 1. Jakarta : KARS.

Latuconsina, N. D., Dewi, T. C., \& Susantyo, A. (2019). Tinjauan Pelaksanaan Retensi Sesuai dengan Permenkes RI No.269 Tahun 2008 dan Akreditasi SNARS di RSUD Kanjuruhan Kabupaten Malang. Kampurui Jurnal Kesehatan Masyarakat 1(1), 11-16.

Lestari, N., Bahrudin, M. I., Sudalhar, \& Pratama, T. W. (2019). Evaluasi Pelaksanaan Penyusutan Berkas Rekam Medis Inaktif Di Rumah Sakit Bhayangkara Wahyu Tutuko Bojonegoro. Jurnal Hospital Science 3(2), 612.

Notoatmodjo. (2010). Pengertian Inklusi dan Eksklusi dalam Penelitian. Retrieved from https://www.pengertianmenurutparaahli.net/pe ngertian-kriteria-inklusi-dan-eksklusi-dalampenelitian. Diakses pada 26 Januari 2021.

Nuraini, Y. A., \& Rohmiyati, Y. (2017). Analisis Penyusutan Arsip Rekam Medis Dalam Rangka Penyelamatan Arsip di Rumah Sakit Islam Sultan Agung Semarang. Jurnal Ilmu Perpustakaan 6(3), 641-650.

Peraturan Menteri Kesehatan Republik Indonesia (2008). PerMenKes RI No.269/MENKES/PER/III/2008 tentang rekam medis. Jakarta: Kementrian Kesehatan.

Rahayu, D. (2012). Tinjauan Pelaksanaan Penyusutan Berkas Rekam Medis Inaktif Di 
Siloam Hospital Kebon Jeruk [KTI]. Jakarta : Universitas Esa Unggul.

Sholikhah, D. E., \& Hastuti, N. M. (2017). Pelaksanaan Retensi Dokumen Rekam Medis Aktif dan Inaktif di RSUD K.R.M.T Wongsonegoro Semarang. Jurnal Rekam Medis dan Informasi Kesehatan 11(2).

Sudira, P. (2016). Panduan Pencarian Literatur Medis. Bali: Buku Panduan Basic Clinical Skills.

Sudra, R. I. (2013). Rekam Medis . Tangerang Selatan : Universitas Terbuka.

Susilo, J., \& Anjani, S. (2019). Tinjauan Prosedur Pemilahan Dokumen Rekam Medis Non Aktif Pada Departemen Filing di RSUD Kelet Jepara Tahun 2019. Visikes : Jurnal Kesehatan Masyarakat 18(2).
Zainal Abidin, M. H. (2018). Identifikasi Berkas Rekam Medis Aktif Ke Inaktif Di Rumah Sakit Umum Daerah Kota Mataram Tahun 2017. Quality Assurance and Health Information Management 2(1). 